Int. J. Dev. Biol. 56: 867-875 (2012)

doi: $10.1387 / \mathrm{ijdb} .120152 \mathrm{gk}$

\title{
DNA methylation establishment during oocyte growth: mechanisms and significance
}

\author{
SHIN-ICHI TOMIZAWA ${ }^{1}$, JOANNA NOWACKA-WOSZUK ${ }^{1,2}$ and GAVIN KELSEY*,1,3 \\ ${ }^{1}$ Epigenetics Programme, The Babraham Institute, Cambridge, U.K., \\ ${ }^{2}$ Department of Genetics and Animal Breeding, Poznan University of Life Sciences, Poznan, Poland and \\ ${ }^{3}$ Centre for Trophoblast Research, University of Cambridge, Cambridge, U.K.
}

\begin{abstract}
DNA methylation in the oocyte has a particular significance: it may contribute to gene regulation in the oocyte and marks specific genes for activity in the embryo, as in the case of imprinted genes. Despite the fundamental importance of DNA methylation established in the oocyte, knowledge of the mechanisms by which it is conferred and how much is stably maintained in the embryo has remained very limited. Next generation sequencing approaches have dramatically altered our views on DNA methylation in oocytes. They have revealed that most methylation occurs in gene bodies in the oocyte. This observation ties in with genetic evidence showing that transcription is essential for methylation of imprinted genes, and is consistent with a model in which DNA methyltransferases are recruited by the histone modification patterns laid down by transcription events. These findings lead to a new perspective that transcription events dictate the placing and timing of methylation in specific genes and suggest a mechanism by which methylation could be coordinated by the events and factors regulating oocyte growth. With these new insights into the de novo methylation mechanism and new methods that allow high resolution profiling of DNA methylation in oocytes, we should be in a position to investigate whether and how DNA methylation errors could arise in association with assisted reproduction technologies or in response to exposure to environmental toxins.
\end{abstract}

KEY WORDS: DNA methylation, histone modification, epigenomics, germ cell, genomic imprinting

\section{Introduction}

Epigenetic modifications of the DNA (cytosine methylation, cytosine hydroxymethylation) or chromatin (post-translation modification of histones) confer an additional layer of information on the DNA that influences the accessibility of the nucleotide sequence to nuclear processes such as gene transcription. The epigenome - the summation of epigenetic modifications across the genome - thus constitutes a fundamental component of the mechanism by which genome information is organised, adapted and interpreted. Some epigenetic modifications, notably cytosine methylation, can be propagated to the daughter cells at DNA replication to provide a long-term memory of earlier decisions, for example, gene activation or repression events during lineage specification, whilst others are more dynamically controlled in response to extrinsic signals. Epigenetic modifications thus dictate genome function, but also provide a marker of developmental history, experience or changing external environments that can instruct or constrain later responses.
Epigenetic information has a special significance in germ cells. The mature oocyte and sperm have unique epigenomes reflecting their status as highly differentiated and phenotypically distinct cells, but

Abbreviations used in this paper: ART, assisted reproduction technologies; BS-Seq, whole genome bisulphite sequencing;ChIP-Seq, chromatin immunoprecipitation combined with next generation sequencing;Dnmt1, DNA methyltransferase 1;Dnmt3a, DNA methyltransferase 3a;Dnmt3b, DNA methyltransferase 3b;Dnmt3L, DNA methyltransferase 3-like;gDMR, germline differentially methylated region;GV, germinal vesicle; H3K4, histone H3 lysine-4;H3K36, histone H3 lysine-36;ICR, imprinted control region; Kap1, KRAB-associated protein 1; Kdm1b/KDM1B, lysine-specific demethylase 1b;KRAB, Krüppel-associated box;MII, metaphase II; mRNA-Seq, mRNA content analysis by next generation sequencing; NLRP2, Nucleotide-binding oligomerization domain, leucine rich repeat (NLR) and pyrin domain containing protein-2; NLRP7, Nucleotide-binding oligomerization domain, leucine rich repeat (NLR) and pyrin domain; containing protein-7; PHD, plant homeodomain; RRBS, reduced representation bisulphite sequencing; Setd2, Set domain containing 2; SETDB1, Set domain, bifurcated 1; Tet, ten-eleven translocation (Tet) methylcytosine dioxygenase; Zfp57/ZFP57, zinc-finger protein 57.

*Address correspondence to: Gavin Kelsey. Epigenetics Programme, The Babraham Institute, Cambridge, CB22 3AT, United Kingdom.
e-mail: gavin.kelsey@ babraham.ac.uk -Tel: +44-1223-496332 - Fax: +44-1223-496022 - web: http://www.babraham.ac.uk/epigenetics/kelsey.html

Final, author-corrected PDF published online: 18 January 2013.

ISSN: Online 1696-3547, Print 0214-6282 
some of their epigenetic information is passed on to the embryo in a stable manner, such that epigenetic marks established in the gametes can influence gene activity throughout the lifetime of the offspring. This applies classically in the case of imprinted genes in mammals but may also occur, perhaps to a variable extent, at other DNA sequences. Because epigenetic decisions or errors made in gametes can be transmitted to the embryo, it is imperative that we understand the processes that establish and maintain the epigenetic patterning of our gametes and identify where vulnerabilities might lie. Here, we review very recent advances in our understanding of the distribution of DNA methylation in the oocyte, the mechanisms by which it is established, and the purposes it has in the oocyte and beyond.

\section{Principles of DNA methylation}

DNA methylation is the archetypal epigenetic mark (Jones, 2012). In mammals, DNA methylation is found on cytosines primarily in the context of CpG dinucleotides. Because methylation normally occurs on the cytosine on both DNA strands in CpGs it is often referred to as symmetric. Importantly, symmetric methylation can be maintained after DNA replication because the 'hemimethylated' DNA so formed is the perfect template for the maintenance DNA methyltransferase Dnmt1 to add a methyl group to the cytosine on the nascent strand opposite the methylated cystosine on the parental strand. This default maintenance process has the potential to propagate a DNA methylation state across countless DNA replication events, such that DNA methylation can provide a long-term, epigenetic memory. DNA methylation can also occur outside of CpGs, in which case it is referred to as non-CpG or asymmetric methylation. Although initially considered absent or rare in mammalian DNA, there is increasing evidence that non$\mathrm{CpG}$ methylation is present at appreciable frequencies in selected cell types, particularly those such as embryonic stem cells (Lister et al., 2009) that have high levels of activity of the de novo DNA methyltransferases Dnmt3a and Dnmt3b, since these enzymes do not exclusively methylate cytosines in CpGs. However, the functional role of non-CpG methylation is largely unclear, in particular because non-CpG methylation cannot be copied directly onto the daughter DNA strands after replication by Dnmt1. Non-CpG methylation is especially abundant in oocyte DNA (Tomizawa et al., 2011; Kobayashi et al., 2012), where it can be considered to be the result of accumulation of the non- $\mathrm{CpG}$ methylation activity of the de novo methyltransferases acting in a non-replicating cell. Whether it has any functional significance is not clear: there is no evidence that prominent sites of non-CpG methylation in oocytes retain high levels of methylation after fertilisation in preimplantation embryos (Tomizawa et al., 2011; Kobayashi et al., 2012).

In the mammalian genome as a whole, most CpG sites are methylated. This includes CpGs in intragenic and intergenic locations and most interspersed repetitive elements. One class of elements that escapes the general hypermethylation are $\mathrm{CpG}$ islands (Deaton and Bird, 2011). These are short segments of DNA a few hundred base pairs to several kilobases in length in which CpGs are especially enriched (or correctly put, not depleted in relation to the base composition of the genome). Many promoters reside within $\mathrm{CpG}$ islands and even those CpG islands not mapping at canonical transcription start sites might signify alternative promoters (Illingworth et al., 2010). Whilst the great majority of CpG islands are constitutively unmethylated in somatic cells, notable exceptions are the $\mathrm{CpG}$ islands on the inactive $\mathrm{X}$ chromosome in females and $\mathrm{CpG}$ islands at the control regions of imprinted genes, which are methylated on one parental allele. In addition, around ten percent of CpG islands are methylated tissue-specifically. These properties make the epigenetic status of $\mathrm{CpG}$ islands of particular significance. In addition to CpG islands, active promoters and other putative regulatory sequences have been identified which retain a low level of methylation in a cell-specific manner (Stadler et al., 2011). Although the pattern of DNA methylation will differ in detail between different types of somatic cell, the general principle is likely to be the same. The oocyte, however, appears to have a distinct methylation profile, in which methylation occurs predominantly in gene bodies (Kobayashi et al., 2012), the significance of which is discussed in more detail below.

DNA methylation can be removed by two mechanisms, so-called passive and active demethylation. Passive demethylation involves the failure to methylate the nascent DNA strand after replication, such that a state of hemimethylation remains and, with subsequent DNA replication and cell division, the methylated state becomes progressively diluted from the population over time. The mechanisms responsible for active demethylation that occurs outside the context of DNA replication remain somewhat controversial, but recent work has highlighted the role of oxidative conversion of 5-methylcytosine to 5-hydroxymethylcytosine and subsequent derivatives catalysed by members of the ten-eleven translocation (Tet) family of proteins (Ficz et al., 2011). Apart from the fact that pre-existing DNA methylation profiles are erased early in germ cell specification, whether there is any active turnover of DNA methylation in oocytes once methylation patterns start to become established is not known. Members of the Tet family (Tet3) are highly expressed in oocytes, but it is possible that they function only after fertilisation to contribute to genome-wide reprogramming of methylation in the zygote and during early cleavage divisions (Gu et al., 2011).

Because of the profound effect DNA methylation can have on how DNA sequence is read by transcriptional regulators and because DNA methylation patterns can be copied at DNA replication, methylation in the oocyte has a particular significance. It could have a direct impact on how genes are expressed in the oocyte and DNA methylation deposited on genes in the oocyte can influence how genes are expressed in the embryo. This is obviously the case for imprinted genes (Ferguson-Smith, 2011). These are genes for which only one allele is normally expressed because their control regions (ICRs) are methylated on one parental allele. This monoallelic methylation has its origin in the gametes (hence the alternative term germline differentially methylated region, gDMR) and most imprinted gDMRs are methylated in oocytes and not sperm (Tomizawa et al., 2011). Imprinted genes represent a unique class of gene, in which DNA methylation differences between oocyte and sperm are fully maintained after fertilisation and throughout the lifetime of the offspring. This combination of gametic methylation difference and faithful maintenance of parent-of-origin methylation in the preimplantation embryo at a time that most of the rest of the genome is comprehensively losing methylation sets imprinted genes apart. Although only a very small fraction of our genome is imprinted (representing 100 genes and nineteen characterised imprinted gDMRs), imprinting does provide a precedent that functionally significant epigenetic states can be transmitted from parent 
to offspring. It is possible that epigenetic states outside of classical imprinted genes could be passed from mother to offspring, and this could include epigenetic variation caused by genetic factors or by nutritional or environmental factors, but the existence and extent of such intergenerational epigenetic inheritance remain to be documented. Both for the robustness of imprinting and for the possibility of transmission of an acquired epigenetic state, it is vitally important that we understand how DNA methylation is established in oocytes and what processes could alter the normal methylation patterning of oocytes.

Although DNA methylation is still the best understood epigenetic mark, it cannot be considered in isolation from other epigenetic marks, such as post-transcriptional modifications of histones. A multitude of histone modifications have now been characterised (acetylation, methylation, phosphorylation, ubiqitination, etc.) and how they partition between active and inactive genes and regulatory features. However, the extent to which histone modification states are passed on through DNA replication is unclear and the mechanisms that could provide a memory of histone modification state remain to be fully elucidated (Margueron and Reinberg, 2010). Whereas next generation sequencing has begun to reveal in great precision the location of DNA methylation in the oocyte genome (Smallwood et al., 2011; Kobayashi et al., 2012; Smith et al., 2012), this information is almost completely lacking for histone modifications, because mapping histone modifications still requires far larger numbers of cells than the numbers of oocytes that can be readily obtained. However, it is very likely that histone modification state plays a major role in determining the placement of cytosine methylation in the oocyte genome (as detailed below), so there is a need to understand the distributions of histone modifications and the factors that determine them in oocytes. It is also possible that histone modifications present in oocyte chromatin can be retained on maternal chromosomes after fertilisation and influence the activity of genes in the zygote and early embryo (Kelsey and Feil, 2013), so knowledge of chromatin organisation in oocytes is also important from that point of view.

\section{The mechanistic basis of de novo DNA methylation in oocytes}

Gametogenesis in mammals is characterised by extensive epigenetic reprogramming events that, in the first instance, erase the pre-existing epigenetic profile of the somatic cells from which germ cells are specified in the early embryo and, then, elaborate the epigenetic patterns of the mature gametes (Smallwood and Kelsey, 2012). Thus, by the time primordial germ cells have migrated to the genital ridge, it is thought that they are largely devoid of DNA methylation (Guibert et al., 2012). In the mouse female germline, the period that DNA methylation is re-established is after birth during oocyte growth (Fig. 1). Thus, it occurs in oocytes that have entered meiosis and have arrested in the diplotene stage of meiotic prophase I. Many studies have used the gDMRs of imprinted genes in the mouse as a model for de novo methylation (but with the assumption that gDMR methylation may be a rather specific mechanism). These studies have established that the onset of gDMR methylation coincides with the transition from primary to secondary follicles and is dependent on oocyte size, such that gain in methylation is detected in oocytes once they have attained a diameter of at least $\sim 50 \mu \mathrm{m}$ and is complete by the germinal vesicle (GV) stage when oocytes become transcriptionally silent (Lucifero et al., 2004; Hiura et al., 2006; Denomme et al., 2012). The more limited analyses that has necessarily been done in human oocytes show that gDMR methylation occurs during similar stages in human oocytes (Sato et al., 2007) At least in the mouse, there is no evidence for substantial gain of methylation as late as oocyte maturation. Recent genome-wide studies support the conclusion that the major phase of de novo methylation occurs in growing oocytes and that prior to the onset of oocyte growth the genome has a very low level of methylation (Smallwood et al., 2011). From a sequence point of view, gDMRs can be considered to be $\mathrm{CpG}$ island-like elements, each comprising several hundred CpG dinucleotides covering upto a few kilobases of DNA and in which every $\mathrm{CpG}$ is methylated by the time oocytes are fully grown (Tomizawa et al., 2011). Interestingly, de novo methylation of gDMRs may not be synchronous, with evidence that different gDMRs start to acquire methylation in different size populations of oocytes (Lucifero et al., 2004; Hiura et al., 2006; Denomme et al., 2012). This molecular observation is consistent with elegant nuclear transfer studies that provided evidence that different imprinted domains acquire the competence to become imprinted at different times in oocyte growth (Obata and Kono 2002).

The de novo DNA methyltransferase universally responsible for gDMR methylation in oocytes is Dnmt3a (Kaneda et al., 2004); the sister protein Dnmt3b appears not to be required for DNA methylation in oocytes (Kaneda et al., 2010). gDMR methylation also requires the presence of Dnmt3L (Bourc'his et al., 2001; Hata et al., 2002), a catalytically inactive, related protein that forms a heterotetrameric complex with Dnmt3a (Jia et al., 2007). Although Dnmt3L was initially thought of as a factor required specifically to methylate imprinted gDMRs, and to enhance the activity of Dnmt3a rather than being an essential cofactor (Chedin et al., 2002), these assumptions have to be revised in the light of genome-wide methylation analysis. First, profiling of $\mathrm{CpG}$ island methylation in oocytes by reduced representation bisulphite se-

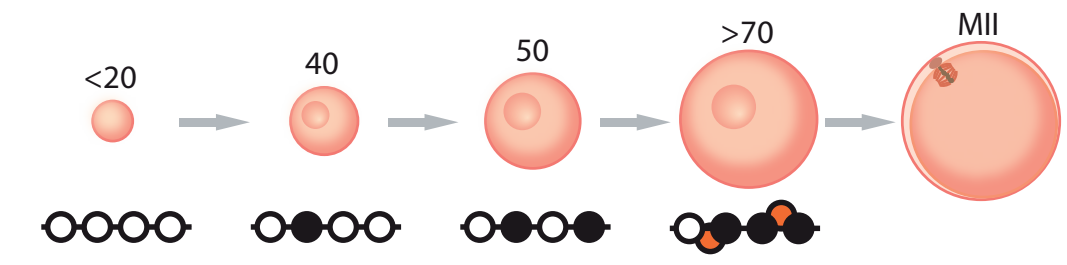

Fig. 1. Establishment of DNA methylation during oocyte growth. DNA methylation occurs in growing oocytes, with the onset of methylation coinciding with the transition from primary to secondary follicles or as oocytes attain a diameter of $>50 \mu \mathrm{m}$. At any particular sequence (a typical gDMR of an imprinted gene is depicted here, with individual CpGs represented by circles and black circles representing methylation), DNA methylation appears to be a progressive process, such that partially methylated intermediates can be detected in populations of oocytes. CpG methylation is completed by the time oocytes are $>70 \mu \mathrm{m}$. Fully grown oocytes also accumulate methylation at cytosines outside CpG dinucleotides (red circles) although, in contrast to CpG sites in gDMRs which all become methylated, non-CpG sites are less consistently methylated (Tomizawa et al., 2011). 
quencing (RRBS) identified $>1000 \mathrm{CpG}$ islands fully methylated in GV or metaphase II (MII) oocytes and demonstrated that apart from a handful, all depended equally on Dnmt3a and Dnmt3L for methylation (Smallwood et al., 2011). (The handful of exceptions comprised $\mathrm{CpG}$ islands that were already methylated before the onset of oocyte growth and before the appearance of Dnmt3a and Dnmt3L; they might represent rare elements that do not become demethylated during the genome-wide demethylation that occurs in primordial germ cells.) Second, whole genome shotgun bisulphite sequencing (BS-Seq) demonstrated that methylation in oocytes occurs predominantly over gene bodies and that all such gene body methylation depends on Dnmt3L (Kobayashi et al., 2012). In the absence of Dnmt3L many, but not all, interspersed repeats are also hypomethylated.

Apart from Dnmt3a and Dnmt3L, there are two other factors that have been demonstrated to be necessary for gDMR methylation in oocytes in mice, but neither is required universally. Oocytes lacking the histone $\mathrm{H} 3$ lysine-4 demethylase $\mathrm{Kdm} 1 \mathrm{~b}$ (also known as Aof1 or Lsd2) fail to methylate four out of seven of the gDMRs examined (Ciccone et al., 2009). The reason for this selectivity is not understood; possible mechanistic links between $\mathrm{Kdm} 1 \mathrm{~b}$ and DNA methylation are discussed below. Oocytes lacking the KRAB-zinc finger protein Zfp57 fail to methylate the gDMR in the Snrpn locus, but not at four other imprinted loci tested (Li et al., 2008). Zfp57 is a sequence-specific DNA-binding factor which, via binding with the repressor Kap1 (also known as TRIM28, Tif1b or KRIP-1), interacts with several epigenetic modifiers, including the H3K9 methyltransferase SETDB1 (also known as ESET), as well as Dnmt3a (Quenneville et al., 2011; Zuo et al., 2012). However, its binding motif is present in all gDMRs and it binds when methylated, so how Zfp57 is involved in de novo methylation of a specific gDMR is unclear. Zfp57 is essential in preimplantation embryos for maintaining methylation of all gDMRs, both in mice and humans (Li et al., 2008; Mackay et al., 2008; Quenneville et al., 2011). Human studies have also identified additional proteins necessary for gDMR methylation. Mutations in NLRP7 and C6orf221 result in familial biparental hydatidiform mole, a condition of recurrent pregnancy loss caused by failure to establish DNA methylation multiple imprints in the oocyte or maintain them in the conceptus
(Murdoch et al., 2006; Parry et al., 2011). Mutations in NLRP2 have been found in cases of the imprinted disorder BeckwithWiedemann syndrome in which there is absence of methylation of the KCNQ1OT1 gDMR (Meyer et al., 2009). The mode of action of these proteins in DNA methylation is not understood. NLRP2 and NLRP7 are members of the CATERPILLAR family of proteins, which are involved in intracellular regulation of bacterial-induced inflammation, whilst C6orf221 is part of a family of proteins characterised by an $\mathrm{N}$-terminal $\mathrm{KH}$ domain (K homology domain), which can bind RNA. Based on the properties of related proteins in mice, it has been suggested that NLRP7 and C6orf221 may form part of a complex that may help to provide structural organisation of cytoplasmic processes in the oocyte (Parry et al., 2011). Given this cytoplasmic location, it will be intriguing to determine how these proteins ultimately regulate DNA methylation, but the absence of direct orthologues in the mouse makes functional studies difficult. Strictly, it is not possible to infer at this time whether NLRP2, NLRP7 and C6orf221 function in methylation establishment in the oocyte or methylation maintenance in the zygote as a result of maternal protein provided from the oocyte.

\section{Transcription determines DNA methylation in oocytes}

A question that has occupied the imprinting community in particular for a number of years is how Dnmt3a and Dnmt3L are targeted to methylate gDMRs. In light of recent mechanistic and methylation profiling studies, this is probably the wrong way to consider how and where DNA methylation is established in the oocyte. The assumption, which must now be considered flawed, was that Dnmt3a in combination with Dnmt3L was recruited by specific DNA sequence motifs or properties of the DNA sequence, such as regular spacing of CpG dinucleotides (Jia et al., 2007). More likely, the Dnmt3a:Dnmt3L complex methylates DNA in response to the histone modification state of the associated chromatin, and rather than reflecting the underlying DNA sequence, the histone modification status permissive for Dnmt3a:Dnmt3L may be determined to a large extent by transcriptional activity (Smallwood and Kelsey, 2012; Kelsey and Feil, 2013). The first decisive observation in support of a role of transcription in DNA methylation was made for the

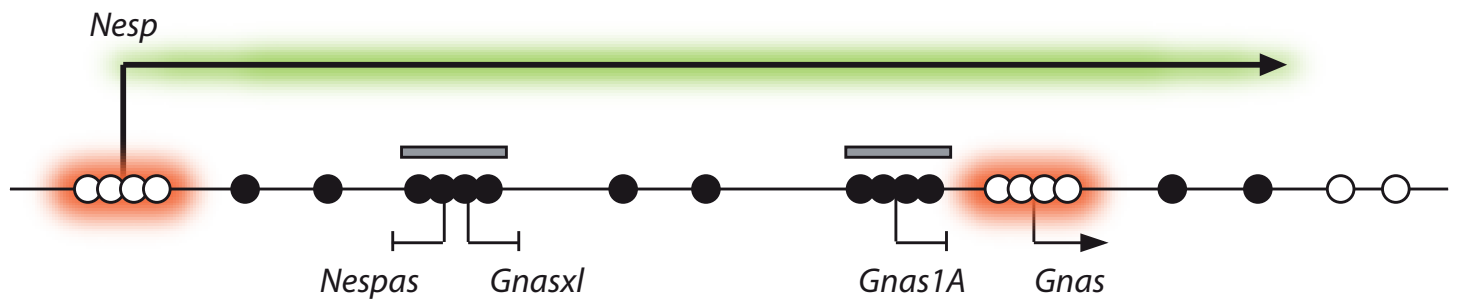

Fig. 2. Transcription is required for DNA methylation at imprinted germline differentially methylated region (gDMRs). The scheme represents the imprinted Gnas locus, for which a requirement for transcription in gDMR methylation was first demonstrated. The locus comprises several alternative transcripts, Gnas, Gnas1A, Gnasxl and Nesp, which initiate from alternative promoters but are part of the same transcription unit, and Nespas, which is transcribed in the opposite direction. The Gnas and Nesp promoters are active during oocyte growth (arrowheads), whereas the Gnas1A, Gnasxl and Nespas promoters are inactive. Importantly, transcription initiating from the Nesp promoter passes through the entire locus, including the gDMRs (grey bars). Preventing Nesp transcription blocks the establishment of methylation of the gDMRs (Chotalia et al., 2009; Fröhlich et al., 2010). Whole genome BS-Seq (Kobayashi et al., 2012) has revealed that the entire transcription unit is methylated (black circles), with the exception of the CpG islands associated with the Gnas and Nesp promoters (white circles). These CpG islands may escape transcription-induced DNA methylation because they are active in oocytes and may bind factors that ensure a chromatin organisation non-permissive for engagement of Dnmt3a:Dnmt3L. It is expected that the same principles apply to all active transcription units in oocytes. 
imprinted locus Gnas. This locus contains two gDMRs upstream of the CpG island promoter for Gnas; somewhat further upstream there is an additional alternative promoter, for the Nesp transcript (Fig. 2). The Nesp promoter is active in growing oocytes, although the encoded Nesp protein does not have an obvious function in oocytes. Importantly, transcription initiating at the Nesp promoter goes through the gDMRs and when transcription is ablated (by deleting the promoter or inserting a transcription termination cassette), methylation of the gDMRs is partially or completely lost (Chotalia et al., 2009; Fröhlich et al., 2010). In human, deletions of the homologous NESP55 promoter region are associated with complete loss of methylation of the DMRs in the GNAS locus when maternally transmitted (Bastepe et al., 2005). A similar requirement for transcription across a gDMR in oocytes for methylation establishment has recently been shown for the Snrpn imprinted locus (Smith et al., 2011). This finding may provide an explanation for why maternally-transmitted deletions in cis but separate from the SNPRN gDMR in humans can result in loss of methylation of the gDMR, which is one molecular cause of Angelman syndrome.

Amajor role for transcription in de novo methylation can now also been inferred from RRBS and BS-Seq data from mouse oocytes. RRBS, which preferentially profiles CpG islands, showed that methylated CpG islands in oocytes were disproportionately located within genes rather than at their 5' ends, as might be expected for CpG islands (Smallwood et al., 2011). This was especially so after inferring gene structures from mRNA-Seq data rather than using conventional gene annotations. BS-Seq data revealed that most DNA methylation in oocytes is within gene bodies and the level of methylation correlates with gene expression level based on mRNA-Seq analysis (Kobayashi et al., 2012). Aside from demonstrating a strong correlation between transcription and methylation, these observations are important in another respect. They suggest that gDMR and intragenic $\mathrm{CpG}$ island methylation is contiguous with and therefore mechanistically similar to gene body methylation. This supports the conclusion that gDMR methylation is not primarily determined by DNA sequence, but rather by location within transcription units. However, an impact of DNA sequence on methylation cannot be excluded, but sequence properties may be more important in determining specific sites to be protected from methylation. Hence, intragenically located $\mathrm{CpG}$ islands associated with active promoters may be protected from the default gene body methylation (Fig. 2; and see Chotalia et al., 2009) by binding activating transcription factors that directly or indirectly recruit histone modifying activities that generate a chromatin state non-permissive to Dnmt3a:Dnmt3L (Kelsey and Feil, 2013).

The conclusion that transcription is a major driver of DNA methylation in oocytes has two important implications. First, it suggests mechanistic models that integrate transcription, transcription-coupled processes of histone modification and the known properties of Dnmt3a:Dnmt3L in relation to their interaction with chromatin. Second, it suggests how DNA methylation may be coordinated by factors that control oocyte growth.

\section{Transcription, transcription-dependent histone modi-} fications and the de novo DNA methylation complex

A fundamentally important finding was that Dnmt3L is sensitive to histone modification state. Via its PHD (plant homeodomain)like domain, Dnmt3L interacts with the amino-terminal tail of histone $\mathrm{H} 3$, but not when lysine at residue 4 is methylated (Fig. 3; Ooi et al., 2007; Hu et al., 2009). Subsequently, it was shown that the PHD domain of Dnmt3a has similar properties (Zhang et al., 2010). This is compatible with an ability to DNA methylate transcriptionally inactive promoters, which are depleted in H3K4 tri- and di-methylation. It also helps explain the observation that some gDMRs fail to become methylated in oocytes lacking the H3K4 demethylase Kdm1b, which is active against H3K4 di- and mono-methylation (Ciccone et al., 2009). Interestingly, it has also been reported that KDM1B in human cells (HeLa) is associated with gene bodies (Fang et al., 2010): if this also applied in oocytes, then transcription-coupled $\mathrm{Kdm} 1 \mathrm{~b}$ activity may be generally required to prepare gene bodies for DNA methylation, including intragenic $\mathrm{CpG}$ islands and gDMRs within transcription units. Since Kdm1b is only readily detected in oocytes from the secondary follicle stage, a possible explanation for why only a subset of gDMRs depend on Kdm1b for DNA methylation is that these gDMRs are normally methylated latest in oocyte growth, so that alternative H3K4 demethylase activities present at earlier stages are required for other gDMRs or transcription units (Ciccone et al., 2009). It will be interesting to investigate whether dependence on Kdm1 b correlates with the time of activity of transcription units in which the gDMRs are located. Dnmt3a is sensitive to additional histone modifications, since its PWWP domain has been shown to bind H3K36me3 (Fig. 3; Dhayalan et al., 2010). This property may be important, because H3K36me3 is a histone modification associated with transcriptional elongation: the major activity responsible for trimethylation of H3K36, Setd2 (also known as HYPB), is associated with the elongating form of RNA polymerase II (Yoh et al., 2008). Thus, reading of the $\mathrm{H} 3 \mathrm{~K} 36 \mathrm{me} 3$ mark by Dnmt3a might account for the preponderance of gene body methylation in oocytes. Given these properties, it might be predicted that transcriptionally active genes, including intragenic $\mathrm{CpG}$ islands and gDMRs associated with inactive promoters, have the combination of histone modifications permissive for Dnmt3a:Dnmt3L engagement: unmethylated H3K4 and trimethylated H3K36 (Fig. 3). However, apart from one ChIP-Seq study in growing oocytes that has shown that $\mathrm{CpG}$ islands destined to become DNA methylated have reduced levels of H3K4me3 (Smallwood et al., 2011), the histone modification status of specific genes in oocytes is not known. The above model (which we have dealt with in greater detail elsewhere, Kelsey and Feil, 2013) will need to be tested by profiling histone modifications in growing oocytes and their dependence on transcription, which is challenging because of the amount of material required for reproducible chromatin immunoprecipitation studies, or genetically by mutating the histone modifier activities involved.

\section{Transcription as a means to coordinate DNA methylation with the control of oocyte growth}

The implication that transcription controls where DNA methylation is deposited in the oocyte genome highlights promoter activity and the transcription factors that determine which promoters are active as having a major role in delineating where, and perhaps when, DNA methylation is laid down in oocytes. Interestingly, we found that many imprinted genes had alternative upstream promoters active in oocytes and it was the activity of these upstream start sites that had the effect of placing the gDMRs within active transcription units to confer their methylation (Chotalia et al., 2009). 
Further, by mRNA-Seq analysis we have found that there is a switch in apparent transcription start site use between fetal germ cells and growing oocytes in many imprinted genes, suggesting that these new promoters are induced by transcription factors that appear during follicle activation or oocyte growth. It will be important to formalise these observations by more refined mapping of transcription start sites and their changes during oocyte development and growth and the temporal relationship with methylation. As noted above, the onset of DNA methylation is known to differ between gDMRs (Lucifero et al., 2004; Hiura et al., 2006; Denomme et al., 2012), so one reason for this asynchrony could be the times at which transcription events that traverse gDMRs are induced during oocyte growth. As an extension of this logic, the signalling pathways that transduce information from the granulosa cells that support oocyte growth could determine which genes become methylated by controlling specific sets of transcription factors. If this were the case, some gene-specific anomalies in oocyte methylation could arise through impairments in specific signalling:transcription factor pathways. It will be important to test this hypothesis to see whether ablating specific transcription factors and impairing the activation of specific transcription units leads to disruption of DNA methylation in a predictable, locus-specific fashion. Although not relating to a signalling pathway or transcription factor, the principle that locus-specific methylation defects can arise through compromised oocyte growth has recently been reported. Oocytes from mice deficient in connexin 37 , which is required for the gap junctions between oocytes and granulosa cells, do not attain full size and fail to gain methylation

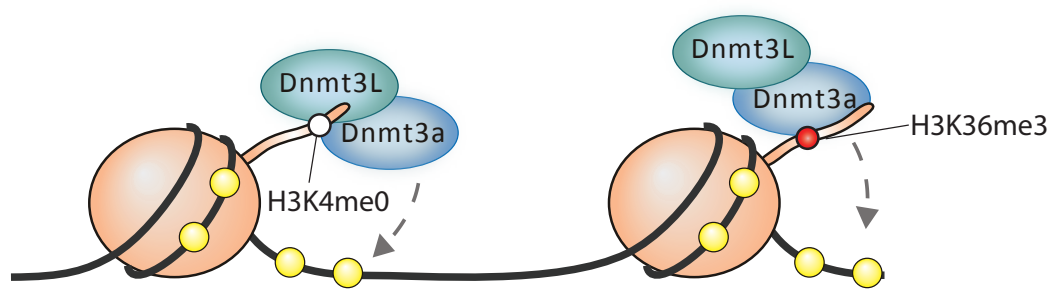
of the Peg1 gDMR, whilst the Peg3 and Snrpn gDMRs are unaffected (Denomme et al., 2012).

\section{The role of DNA methylation in oocytes and its vulner- ability to external factors}

What is the role of DNA methylation in oocytes? Although this might seem a surprising question, now that we understand in greater detail where in the oocyte genome methylation is placed, it is a legitimate one to ask. It should be appreciated that germ cells become globally demethylated early in their specification (Guibert et al., 2012) and, in the case of the female germline, de novo methylation only commences late in the oocyte growth phase, so entry into meiosis, folliculogenesis and the early stages of growth are accomplished without the presence of significant DNAmethylation (in gene bodies, CpG islands and many interspersed repeats). This suggests that DNA-methylation dependent gene silencing is largely dispensable for a great deal of oocyte development. Indeed, depriving oocytes of de novo methylation through genetic ablation of Dnmt3a or Dnmt3L appears to have no gross impact on oocyte development, maturation and competence (Bourc'his et al., 2001; Hata et al., 2002; Kaneda et al., 2004). It has also been shown that DNA methylation has a minimal impact on gene expression in oocytes. mRNA-Seq data comparing postnatal d10 growing oocytes at the onset of de novo methylation with fully grown GV

oocytes suggested that gain of DNA methylation had little effect on the abundance of the associated transcripts (Smallwood et al., 2011). Similarly, there is very little difference in abundance in Dnmt3L-/- oocytes compared with control MII oocytes (Kobayashi et al., 2012). It is not excluded that there are more subtle changes in transcription start site use in oocytes lacking de novo methylation and that methylation may help to suppress cryptic promoters. However, it appears that most promoter silencing in oocytes is accomplished by lack of appropriate transcription factors rather than by DNA methylation. Gene body methylation appears to be a default mechanism rather than an active process regulating promoter activity.

As noted above, some of the DNA methylation established in oocytes does have a vitally important legacy in the embryo. Embryos conceived from Dnmt3a- or Dnmt3L-deficient oocytes develop apparently normally until embryonic day (e) 8, but die by e10 (Bourc'his et al., 2001; Hata et al., 2002; Kaneda et al., 2004). Their demise at this stage has been attributed to dysregulated expression of imprinted genes: without establishment of maternal gDMRs in oocytes, the correct monoallelic expression of most imprinted genes is disrupted, resulting in total loss of expression or loss of imprinted silencing, depending on the locus. But apart from imprinted genes, much gene-specific DNA methylation in oocytes could be considered a bystander effect of little functional significance, since this methylation becomes erased during the 
first embryonic cleavage divisions (Smallwood et al., 2011; Smith et al., 2012). There seems to be a highly effective mechanism in the early embryo to ensure that DNA methylation of gDMRs is maintained, but all other gametic methylation is purged. The fidelity of this process depends largely upon maternal factors provided by the oocyte cytoplasm (e.g., Zfp57, Kap1, Tet3, Stella, Dnmt1o; as reviewed in Kelsey and Feil, 2013), but the selectivity is not fully understood. Whether there is the potential for transmission of DNA methylated states at genes or regulatory sequences beyond imprinted genes remains to be demonstrated.

The possibility of aberrant epigenetic marking of oocytes has been raised in a number of contexts: in relation to assisted reproduction technologies (ART); exposure to environmental toxins, such as the synthetic estrogen bisphenol A (Chao et al., 2012); or in response to maternal nutritional status. As discussed above, DNA methylation establishment is dynamically controlled during oocyte growth, it is regulated proximally by transcription events and, therefore, could be perturbed by any adverse conditions that alter the normal transcription programme of the growing oocyte. Evidence has been presented that children conceived through ART have an increased risk of premature birth, low birth weight and imprinting disorders associated with aberrant methylation of specific gDMRs, although the magnitude of the risk remains a matter of continued debate (reviewed by Laprise, 2009). Epigenetic errors could occur during ART-associated procedures by a number of mechanisms relating to ovarian stimulation or embryo culture: by forcing oocytes to develop more rapidly than normal; by recruiting lower quality oocytes that would normally not ovulate from subfertile donors; or by altering the content of factors that accumulate in the oocyte that are necessary for the correct maintenance of gDMR methylation and epigenetic reprogramming in the preimplantation embryo. Although some studies have reported methylation changes in specific gDMRs in ART individuals who were not ascertained for an imprinted disorder (e.g., Gomes et al., 2009), other moderately sized studies that have screened multiple gDMRs have not found evidence for significantly greater variation in gDMR methylation in children conceived through ART compared with natural conception (Tierling et al., 2010; Rancourt et al., 2012). It is clear that there is a need for sufficiently large and probably longitudinal studies on cohorts of ART-conceived children, but differences in ARTassociated procedures between fertility clinics and inadequate sensitivity or reproducibility of some of the methylation assays employed may both contribute to the lack of consensus between reports at this time.

An effect of superovulation on gDMR methylation is now well documented in the mouse, at least when methylation is ascertained in preimplantation embryos (Market-Velker et al., 2010) or later stages. Both hypomethylation of gDMRs normally methylated in oocytes (Snrpn, Kcnq1ot1 and Peg3) and gain of methylation of gDMRs normally methylated in sperm $(H 19)$ have been observed. Single oocyte analysis showed that these effects do not originate as methylation errors in oocytes (Denomme et al., 2011), and the mosaic and stochastic nature of the methylation changes detected in embryos are more consistent with impaired maintenance during early embryogenesis (de Waal et al., 2012), although another study did detect aberrant gain of methylation of the H19 gDMR in superovulated oocytes but normal methylation of three maternal gDMRs (Peg1, Kcnq1ot1 and Zac1; Sato et al., 2007). Gain of methylation of the $H 19 \mathrm{gDMR}$ and incomplete methylation of the
PEG1 gDMR in human GV and MI oocytes obtained after ovarian stimulation have been observed by single oocyte analysis, but that report lacked the strict control of unstimulated oocytes ascertained by the same method (Sato et al., 2007).

\section{Concluding remarks}

The past couple of years have revolutionised our knowledge of DNA methylation in oocytes. From next generation sequencing mapping of DNA methylation and functional studies in the mouse, we now have very detailed information about the distribution of methylation in the oocyte genome and a good molecular understanding of the processes that confer methylation. These advances have highlighted transcription as a major determinant of DNAmethylation, most likely by generating a chromatin state permissive for DNA methyltransferase activity. This brings new perspectives about how DNA methylation of individual genes may be coordinated by the events that control oocyte growth, acting both within the oocyte and from supporting somatic cells. We have also learnt that most DNA methylation in oocytes may be dispensable and is probably only required to mark a subset of genes for activity in the embryo, such as imprinted genes. More work is needed to understand the extent to which the oocyte epigenome is susceptible to procedures used in ART, can be modified by diet, or harmed by environmental factors, and what the long term consequences of such effects are. We have just begun to develop the tools that allow us to acquire high resolution, quantitative information on DNA methylation from small numbers of oocytes, but there is a continued need for further developments, for example, single oocyte analysis, and many other types of molecular analyses will continue to be a challenge.

\section{Acknowledgements}

Work in Gavin Kelsey's group is supported by the Biotechnology and Biological Sciences Research Council and the Medical Research Council of the United Kingdom and by the European Union. Joanna NowackaWoszuk is supported by a post-doctoral fellowship founded by Polish Ministry of Science and Higher Education (Mobility Plus Programme, no: 609/MOB/2011/0).

\section{References}

BASTEPE, M., FRÖHLICH, L.F., LINGLART, A., ABU-ZAHRA, H.S., TOJO, K., WARD, L.M. and JÜPPNER, H. (2005). Deletion of the NESP55 differentially methylated region causes loss of maternal GNAS imprints and pseudohypoparathyroidism type Ib. Nat Genet 37: 25-27.

BOURC'HIS, D., XU, G.L., LIN, C.S., BOLLMAN, B. and BESTOR, T.H. (2001). Dnmt3L and the establishment of maternal genomic imprints. Science 294: 2536-2539.

CHAO, H.H., ZHANG, X.F., CHEN, B., PAN, B., ZHANG, L.J., LI, L., SUN, X.F., SHI, Q.H., and SHEN, W. (2012). Bisphenol A exposure modifies methylation of imprinted genes in mouse oocytes via the estrogen receptor signaling pathway. Histochem Cell Biol 137: 249-259.

CHEDIN, F., LIEBER, M.R., and HSIEH, C.L. (2002). The DNA methyltransferase-like protein DNMT3L stimulates de novo methylation by Dnmt3a. Proc Natl Acad Sci USA 99: 16916-16921.

CHOTALIA, M., SMALLWOOD, S. A., RUF, N., DAWSON, C., LUCIFERO, D., FRONTERA, M., JAMES, K., DEAN, W. and KELSEY, G. (2009). Transcription is required for establishment of germline methylation marks at imprinted genes. Genes Dev 23: 105-117.

CICCONE, D. N., SU, H., HEVI, S., GAY, F., LEI, H., BAJKO, J., XU, G., LI, E. and CHEN, T. (2009). KDM1B is a histone H3K4 demethylase required to establish maternal genomic imprints. Nature 461: 415-418.

DEATON, A.M., and BIRD, A. (2011). CpG islands and the regulation of transcription. 
Genes Dev 25: 1010-1022.

DENOMME, M.M., ZHANG, L., and MANN, M.R. (2011). Embryonic imprinting perturbations do not originate from superovulation-induced defects in DNA methylation acquisition. Fertil Steril 96: 734-738.

DENOMME, M.M., WHITE, C.R., GILLIO-MEINA, C., MACDONALD, W.A., DEROO, B.J., KIDDER, G.M., and MANN, M.R. (2012). Compromised fertility disrupts Peg1 but not Snrpn and Peg3 imprinted methylation acquisition in mouse oocytes. Front Genet 3: 129

DE WAAL, E., YAMAZAKI, Y., INGALE, P., BARTOLOMEI, M.S., YANAGIMACHI, R., and MCCARREY, J.R. (2012). Gonadotropin stimulation contributes to an increased incidence of epimutations in ICSI-derived mice. Hum Mol Genet 21: 4460-4472.

DHAYALAN, A., RAJAVELU, A., RATHERT, P., TAMAS, R., JURKOWSKA, R.Z., RAGOZIN, S. and JELTSCH, A. (2010). The Dnmt3a PWWP domain reads histone 3 lysine 36 trimethylation and guides DNA methylation. $J$ Biol Chem 285: 26114-26120.

FANG, R., BARBERA, A.J., XU, Y., RUTENBERG, M., LEONOR, T., BI, Q., LAN, F., MEI, P., YUAN, G.C., LIAN, C. PENG, J., CHENG, D., SUI, G., KAISER, U.B., SHI, Y. and SHI, Y.G. (2010). Human LSD2/KDM1b/AOF1 regulates gene transcription by modulating intragenic $\mathrm{H} 3 \mathrm{~K} 4 \mathrm{me} 2$ methylation. Mol Cell 39: 2122-233.

FERGUSON-SMITH,A.C. (2011). Genomic imprinting: the emergence of an epigenetic paradigm. Nat Rev Genet 12: 565-575.

FICZ, G., BRANCO, M.R., SEISENBERGER, S., SANTOS, F., KRUEGER, F., HORE, T.A., MARQUES, C.J., ANDREWS, S. and REIK, W. (2011). Dynamic regulation of 5-hydroxymethylcytosine in mouse ES cells and during differentiation. Nature 473: 398-402.

FRÖHLICH, L.F., MRAKOVCIC, M., STEINBORN, R., CHUNG, U.I., BASTEPE, M. and JÜPPNER, H. (2010). Targeted deletion of the Nesp55 DMR defines another Gnas imprinting control region and provides a mouse model of autosomal dominant PHP-Ib. Proc Natl Acad Sci USA 107: 9275-9280.

GOMES, M.V., HUBER, J., FERRIANI, R.A., AMARAL NETO, A.M., and RAMOS, E.S. (2009). Abnormal methylation at the KvDMR1 imprinting control region in clinically normal children conceived by assisted reproductive technologies. Mol Hum Reprod 15: 471-477.

GU, T.P., GUO, F., YANG, H., WU, H.P., XU, G.F., LIU, W., XIE, Z.G., SHI, L., HE, X., JIN, S.G., IQBAL, K., SHI, Y.G., DENG, Z., SZABÓ, P.E., PFEIFER, G.P., LI, J. and $X U, G$.L. (2011). The role of Tet3 DNA dioxygenase in epigenetic reprogramming by oocytes. Nature 477: 606-610.

GUIBERT, S., FORNÉ, T. and WEBER, M. (2012). Global profiling of DNA methylation erasure in mouse primordial germ cells. Genome Res 22: 633-641.

HATA, K., OKANO, M., LEI, H. and LI, E. (2002). Dnmt3L cooperates with the Dnmt3 family of de novo DNA methyltransferases to establish maternal imprints in mice. Development 129: 1983-1993.

HIURA, H., OBATA, Y., KOMIYAMA, J., SHIRAI, M. and KONO, T. (2006). Oocyte growth-dependent progression of maternal imprinting in mice. Genes Cells 11: 353-361.

HU, J.L., ZHOU, B.O., ZHANG, R.R., ZHANG, K.L., ZHOU, J.Q., and XU, G.L. (2009). The $\mathrm{N}$-terminus of histone $\mathrm{H} 3$ is required for de novo DNA methylation in chromatin. Proc Natl Acad Sci USA 106: 22187-22192.

ILLINGWORTH, R.S., GRUENEWALD-SCHNEIDER, U., WEBB, S., KERR, A.R., JAMES, K.D., TURNER, D.J., SMITH, C., HARRISON, D.J., ANDREWS, R. and BIRD, A.P. (2010). Orphan CpG islands identify numerous conserved promoters in the mammalian genome. PLoS Genet 6: e1001134.

JIA, D., JURKOWSKA, R. Z., ZHANG, X., JELTSCH, A. and CHENG, X. (2007) Structure of Dnmt3a bound to Dnmt3L suggests a model for de novo DNA methylation. Nature 449: 248-251.

JONES, P.A. (2012). Functions of DNA methylation: islands, start sites, gene bodies and beyond. Nat Rev Genet 13: 484-492.

KANEDA, M., OKANO, M., HATA, K., SADO, T., TSUJIMOTO, N., LI, E. and SASAKI, H. (2004) Essential role for de novo DNA methyltransferase Dnmt3a in paternal and maternal imprinting. Nature 429: 900-903.

KANEDA, M., HIRASAWA, R., CHIBA, H., OKANO, M., LI, E., and SASAKI, H. (2010). Genetic evidence for Dnmt3a-dependent imprinting during oocyte growth obtained by conditional knockout with Zp3-Cre and complete exclusion of Dnmt3b by chimera formation. Genes Cells 15: 169-179.

KELSEY, G., and FEIL, R. (2013). New insights into establishment and maintenance of DNA methylation imprints in mammals. Phil Trans R Soc B. 368: 20110336. doi: 10.1098/rstb.2011.0336

KOBAYASHI, H., SAKURAI, T., IMAI, M., TAKAHASHI, N., FUKUDA, A., YAYOI, O. SATO, S., NAKABAYASHI, K., HATA, K., SOTOMARU, Y. SUZUKI, Y., and KONO, T. (2012). Contribution of intragenic DNA methylation in mouse gametic DNA methylomes to establish oocyte-specific heritable marks. PLoS Genet8: e1002440.

LAPRISE, S.L. (2009). Implications of epigenetics and genomic imprinting in assisted reproductive technologies. Mol Reprod Dev 76: 1006-1018.

LI, X., ITO, M., ZHOU, F., YOUNGSON, N., ZUO, X., LEDER, P. and FERGUSONSMITH, A.C. (2008). Amaternal-zygotic effect gene, Zfp57, maintains both maternal and paternal imprints. Dev Cell 15: 547-557.

LISTER R, PELIZZOLA M, DOWEN RH, HAWKINS RD, HON G, TONTI-FILIPPINI J, NERY JR, LEE L, YE Z, NGO QM, EDSALL L, ANTOSIEWICZ-BOURGET J, STEWART R, RUOTTI V, MILLAR AH, THOMSON JA, REN B, ECKER JR. (2009). Human DNA methylomes at base resolution show widespread epigenomic differences. Nature 462: 315-322.

LUCIFERO, D., MANN, M.R., BARTOLOMEI, M.S. and TRASLER, J.M. (2004). Gene-specific timing and epigenetic memory in oocyte imprinting. Hum Mol Genet 13: 839-849.

MACKAY, D.J., CALLAWAY, J.L., MARKS, S.M., WHITE, H.E., ACERINI, C.L., BOONEN, S.E., DAYANIKLI, P., FIRTH, H.V., GOODSHIP, J.A., HAEMERS, A.P, AHNEMANN, J.M., KORDONOURI, O., MASOUD, A.F., OESTERGAARD, E., STORR, J., ELLARD, S., HATTERSLEY, A.T., ROBINSON, D.O., and TEMPLE, I.K. (2008). Hypomethylation of multiple imprinted loci in individuals with transient neonatal diabetes is associated with mutations in ZFP57. Nat Genet 40: 949-951.

MARKET-VELKER, B.A., ZHANG, L., MAGRI, L.S., BONVISSUTO, A.C., and MANN, M.R. (2010). Dual effects of superovulation: loss of maternal and paternal imprinted methylation in a dose-dependent manner. Hum Mol Genet 19: 36-51.

MARGUERON R, REINBERG D. (2010). Chromatin structure and the inheritance of epigenetic information. Nat Rev Genet 11: 285-296.

MEYER, E., LIM, D., PASHA, S., TEE, L.J., RAHMAN, F., YATES, J.R., WOODS C.G., REIK, W. and MAHER, E.R. (2009). Germline mutation in NLRP2 (NALP2) in a familial imprinting disorder (Beckwith-Wiedemann Syndrome). PLoS Genet 5: e1000423.

MURDOCH, S., DJURIC, U., MAZHAR, B., SEOUD, M., KHAN, R., KUICK, R., BAGGA, R., KIRCHEISEN, R., AO, A., RATTI, B., HANASH, S., ROULEAU, G.A. and SLIM, R. (2006). Mutations in NALP7 cause recurrent hydatidiform moles and reproductive wastage in humans. Nat Genet 38: 300-302.

OBATA, Y. and KONO, T. (2002). Maternal primary imprinting is established at a specific time for each gene throughout oocyte growth. J Biol Chem 277: 5285-5289.

OOI, S. K., QIU, C., BERNSTEIN, E., LI, K., JIA, D., YANG, Z., ERDJUMENTBROMAGE, H., TEMPST, P., LIN, S.P., ALLIS, C.D. CHENG, X., and BESTOR, T.H. (2007). DNMT3L connects unmethylated lysine 4 of histone H3 to de novo methylation of DNA. Nature 448: 714-717.

PARRY, D. A., LOGAN, C.V., HAYWARD, B.E., SHIRES, M., LANDOLSI, H., DIGGLE, C., CARR, I., RITTORE, C., TOUITOU, I., PHILIBERT, L. FISHER, R.A., FALLAHIAN, M., HUNTRISS, J.D., PICTON, H.M., MALIK, S., TAYLOR, G. R., JOHNSON, C.A., BONTHRON, D.T., and SHERIDAN, E.G. (2011). Mutations causing familial biparental hydatidiform mole implicate c6orf221 as a possible regulator of genomic imprinting in the human oocyte. Am J Hum Genet 89: 451-458.

QUENNEVILLE, S., VERDE, G., CORSINOTTI, A., KAPOPOULOU, A., JAKOBSSON, J., OFFNER, S., BAGLIVO, I., PEDONE, P.V., GRIMALDI, G., RICCIO, A., and TRONO, D. (2011). In embryonic stem cells, ZFP57/KAP1 recognize a methylated hexanucleotide to affect chromatin and DNA methylation of imprinting control regions. Mol Cell 44: 361-372

RANCOURT, R.C., HARRIS, H.R., and MICHELS, K.B. (2012). Methylation levels at imprinting control regions are not altered with ovulation induction or in vitro fertilization in a birth cohort. Hum Reprod 27: 2208-2216.

SATO, A., OTSU, E., NEGISHI, H., UTSUNOMIYA, T., and ARIMA, T. (2007). Aberrant DNA methylation of imprinted loci in superovulated oocytes. Hum Reprod 22: 26-35.

STADLER, M.B., MURR, R., BURGER, L., IVANEK, R., LIENERT, F., SCHÖLER, A., VAN NIMWEGEN, E., WIRBELAUER, C., OAKELEY, E.J., GAIDATZIS, D., TIWARI, V.K., and SCHÜBELER, D. (2011). DNA-binding factors shape the mouse methylome at distal regulatory regions. Nature 480: 490-495.

SMALLWOOD, S.A. and KELSEY, G. (2012). De novo DNA methylation: a germ cell perspective. Trends Genet 28: 33-42.

SMALLWOOD, S.A., TOMIZAWA, S., KRUEGER, F., RUF, N., CARLI, N., SEGONDS- 
PICHON, A., SATO, S., HATA, K., ANDREWS, S.R. and KELSEY, G. (2011). Dynamic $\mathrm{CpG}$ island methylation landscape in oocytes and preimplantation embryos. Nat Genet 43: 811-814.

SMITH, Z.D., CHAN, M.M., MIKKELSEN, T.S., GU, H., GNIRKE, A., REGEV, A. and MEISSNER, A. (2012). A unique regulatory phase of DNA methylation in the early mammalian embryo. Nature 484: 339-344.

SMITH, E.Y., FUTTNER, C.R., CHAMBERLAIN, S.J., JOHNSTONE, K.A. and RESNICK, J.L. (2011). Transcription is required to establish maternal imprinting at the Prader-Willi syndrome and Angelman syndrome locus. PLoS Genet7: e1002422.

TIERLING, S., SOUREN, N.Y., GRIES, J., LOPORTO, C., GROTH, M., LUTSIK, P., NEITZEL, H., UTZ-BILLING, I., GILLESSEN-KAESBACH, G., KENTENICH, H., GRIESINGER, G., SPERLING, K., SCHWINGER, E., and WALTER, J. (2010). Assisted reproductive technologies do not enhance the variability of DNA methylation imprints in human. $J$ Med Genet 47: 371-376.

TOMIZAWA, S., KOBAYASHI, H., WATANABE, T., ANDREWS, S., HATA, K., KELSEY, G. and SASAKI, H. (2011). Dynamic stage-specific changes in imprinted differen- tially methylated regions during early mammalian development and prevalence of non-CpG methylation in oocytes. Development 138: 811-820.

YOH, S.M., LUCAS, J.S. and JONES, K.A. (2008). The Iws1:Spt6:CTD complex controls cotranscriptional mRNA biosynthesis and HYPB/Setd2-mediated histone H3K36 methylation. Genes Dev 22: 3422-3434.

ZHANG, Y., JURKOWSKA, R., SOEROES, S., RAJAVELU, A., DHAYALAN, A., BOCK, I., RATHERT, P., BRANDT, O., REINHARDT, R., FISCHLE, W. and JELTSCH, A. (2010). Chromatin methylation activity of Dnmt3a and Dnmt3a/3L is guided by interaction of the ADD domain with the histone $\mathrm{H} 3$ tail. Nucleic Acids Res 38 : 4246-4253.

ZUO, X., SHENG, J., LAU, H.T., MCDONALD, C.M., ANDRADE, M., CULLEN, D.E., BELL, F.T., IACOVINO, M., KYBA, M., XU, G., and LI, X. (2012). Zinc finger protein ZFP57 requires its co-factor to recruit DNA methyltransferases and maintains DNA methylation imprint in embryonic stem cells via its transcriptional repression domain. J Biol Chem 287: 2107-2118. 


\section{Further Related Reading, published previously in the Int. J. Dev. Biol.}

\section{Germline stem cells and sex determination in Hydra}

Chiemi Nishimiya-Fujisawa and Satoru Kobayashi

Int. J. Dev. Biol. (2012) 56: 499-508

The Dr-nanos gene is essential for germ cell specification in the planarian Dugesia ryukyuensis Haruka Nakagawa, Hirotsugu Ishizu, Ayako Chinone,Kazuya Kobayashi and Midori Matsumoto Int. J. Dev. Biol. (2012) 56: 165-171

Impaired meiotic competence in putative primordial germ cells produced from mouse embryonic stem cells Marianna Tedesco, Donatella Farini and Massimo De Felici

Int. J. Dev. Biol. (2011) 55: 215-222

A polymorphic, thrombospondin domain-containing lectin is an oocyte marker in Hydractinia: implications for germ cell specification and sex determination Brahim Mali, R. Cathriona Millane, Günter Plickert, Marcus Frohme and Uri Frank Int. J. Dev. Biol. (2011) 55: 103-108

Generation of germ-line chimera zebrafish using primordial germ cells isolated from cultured blastomeres and cryopreserved embryoids

Yutaka Kawakami, Rie Goto-Kazeto, Taiju Saito, Takafumi Fujimoto, Shogo Higaki, Yoshiyuki Takahashi, Katsutoshi Arai and Etsuro Yamaha

Int. J. Dev. Biol. (2010) 54: 1493-1501

In vitro germ cell differentiation during sex differentiation in a teleost fish Tohru Kobayashi

Int. J. Dev. Biol. (2010) 54: 105-111

Differentiation of mouse primordial germ cells into female or male germ cells.

N Nakatsuji and S Chuma

Int. J. Dev. Biol. (2001) 45: 541-548

5 yr ISI Impact Factor $(2011)=2.959$

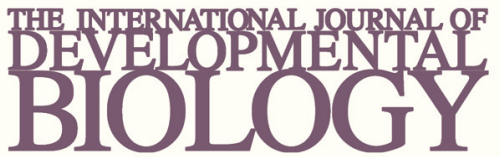

Volume 54 Nos. $6 / 7$
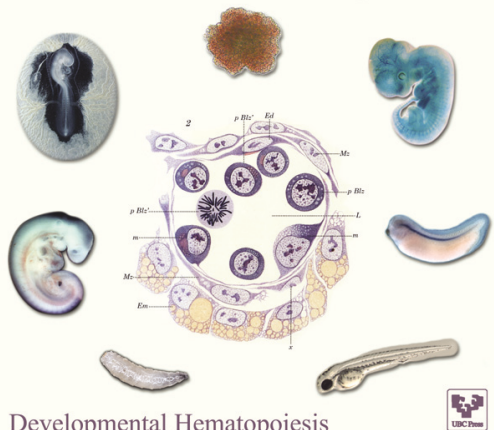

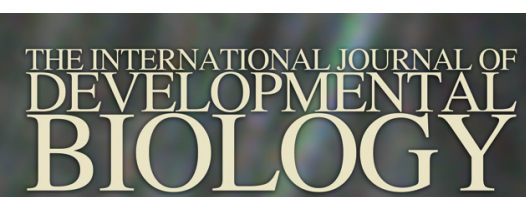

Volume 56 Nos. 1/2/3

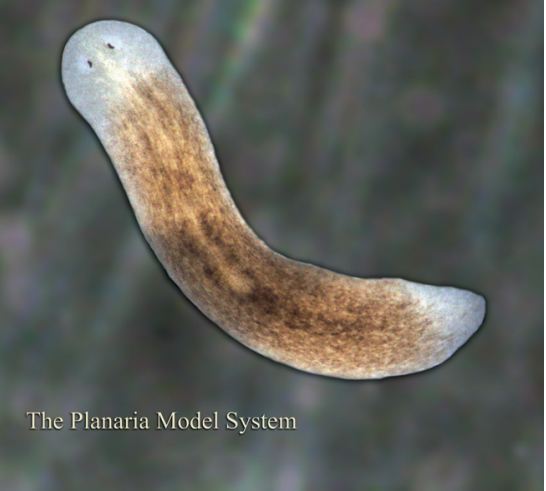

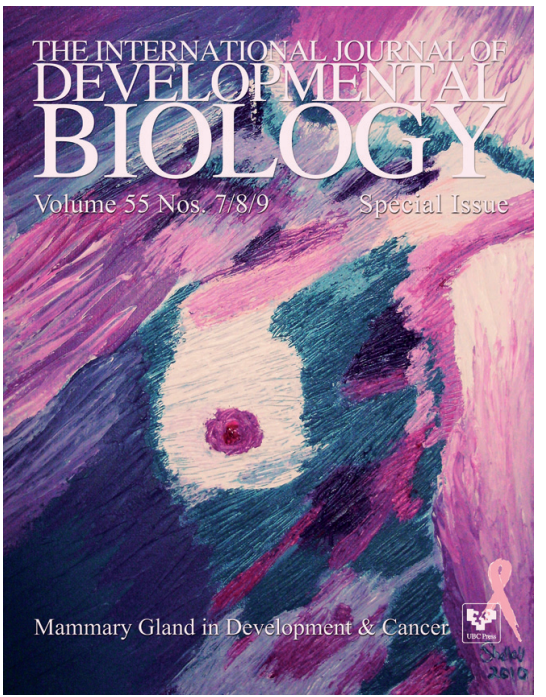
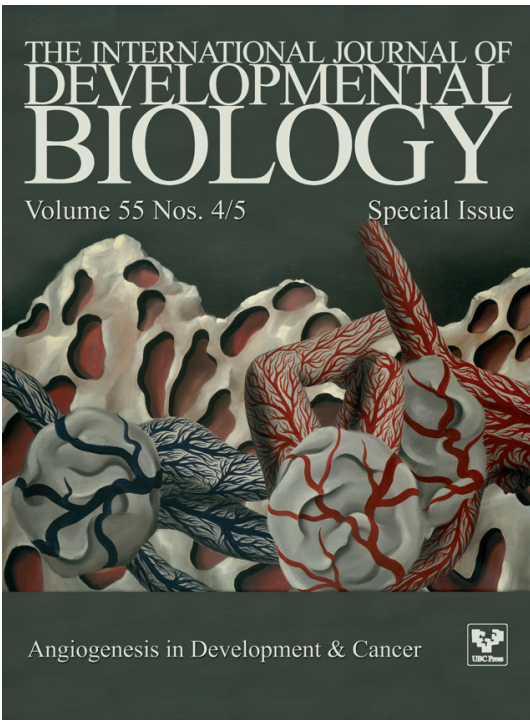